\title{
A new genus of Languriinae from Mexico (Coleoptera, Erotylidae), with comments on the potential mimic phenomenon of some languriines
}

\author{
Zheng-Zhong Huang', Xing-Ke Yang', Si-Qin Ge' \\ I Insititute of Zoology, Chinese Academy of Sciences, 1 Beichen West Road, Chaoyang District, Beijing, \\ 100101, China \\ Corresponding author: Si-Qin Ge (gesq@ioz.ac.cn)
}

Academic editor: A. Kirejtshuk | Received 8 January 2020 | Accepted 13 April 2020 | Published 21 May 2020

http://zoobank.org/028A927D-2570-419D-ACB7-889C767E943E

Citation: Huang Z-Z, Yang X-K, Ge S-Q (2020) A new genus of Languriinae from Mexico (Coleoptera, Erotylidae), with comments on the potential mimic phenomenon of some languriines. ZooKeys 935: 93-101. https://doi. org/10.3897/zookeys.935.49957

\begin{abstract}
A new genus of Languriinae, Tomolanguria Huang, gen. nov. is erected for a single species, Languria aculeata Gorham, 1887 from Mexico. It is similar to the Neotropical genus Languria Latreille, 1802. The differential diagnosis of this new genus is based on the structural features of the elytral apices and slight impressions present on each elytron. Languria aculeata is designated as the type species of the new genus. This species is redescribed and illustrated (all the three specimens examined are shown in the dorsal, ventral, and lateral views). Finally, a mimic relationship between this new genus and genus Paederus Fabricius, 1775 (Staphylinidae) is discussed.
\end{abstract}

\section{Keywords}

Cucujoidea, Neotropical Region, new combination, Tomolanguria

\section{Introduction}

Languria aculeata was first described by Gorham (1887), based on three specimens in the Sallé collection. Martins and Perreira (1965) accomplished a revision of the Neotropical Languriinae, but they did not examine the specimens of $L$. aculeata and just cited Gorham's original description in their work. In 2017, we had a chance to examine specimens of Languriinae, including the syntypes of L. aculeata, in the Natu- 
ral History Museum, London. The elytral structure of $L$. aculeata clearly separates this species from all known Neotropical genera of Languriinae. Hence, we propose a new genus and a new combination for its type species.

\section{Materials and methods}

The type series of Tomolanguria gen. nov., Anadastus ornatus Arrow, 1925, A. pulchellus Arrow, 1925, A. jucundus (Gorham, 1903), Clerolanguria tricolor (Fabricius, 1787), and Stenolanguria tricolor Fowler, 1885 are deposited in the Natural History Museum, London, United Kingdom (BMNH). The holotypes of Paederolanguria holdhausi Mader, 1939 and P. klapperichi Mader, 1955 are deposited in the Naturhistorisches Museum, Basel, Switzerland (NHMB). The holotype of Paederolanguria alternata (Zia, 1959) and non-type specimen of $P$. holdhausi are deposited in the Institute of Zoology of the Chinese Academy of Sciences, Beijing, China (IZCAS). The holotype of Stenolanguria robusta Villiers, 1958 is deposited in the Muséum national d'Histoire naturelle, Paris, France (MNHN). Label data are given with separate lines on labels indicated by / and separate labels by //. Other comments and remarks are in square brackets [].

All photographs were taken with a Canon 5D Mark III digital camera equipped with a Canon MP-E 65 mm lens. The images were stacked with Helicon Focus 6.7.1 and modified in Adobe Photoshop CS6 to correct for contrast, brightness, and imperfections.

Body length was measured from the apices of mandibles to the apices of elytra.

\section{Taxonomy}

Family Erotylidae Latreille, 1802

Subfamily Languriinae Hope, I 840

Tribe Languriini Hope, 1840

Genus Tomolanguria Huang, gen. nov.

http://zoobank.org/9EBD53DE-64BC-4284-8E6E-81BDB8098B34

Type species. Languria aculeata Gorham, 1887.

Diagnosis. The new genus is a member of tribe Languriini, based on the presence of a frontoclypeal suture; the antennal club composed of more than three antennomeres and relatively oval in cross-section. The only species of Tomolanguria can be separated from other languriine genera by the following combination of characters: body length $8.5-9.5 \mathrm{~mm}$, body slender without unified metallic luster, at least prothorax without any metallic luster; antennal club not very dilated; eyes moderate in size and with fine facets; mandibles similar to each other; pronotum finely punctured, without basal foveae; lateral sides of pronotum rounded and prothorax more or less subcylindric, not flattened; elytral epipleura distinct, each elytron with transverse and 
very weak depressions, apices of elytra being produced and strongly tapering, rounded and with several small denticles.

Comparision. The elytral structure, which often shows the differences among genera of Languriinae, is a relatively reliable morphological character. Tomolanguria is closely related to genus Languria Latreille, 1802, sharing with the latter a similar external appearance. From Languria, it can be distinguished by having the antennal club not very dilated; lateral sides of pronotum rounded and prothorax more or less subcylindric; each elytron with transverse and weak depressions, and apices of elytra being more or less produced and strongly tapering, and also with several small denticles. However, the elytral apex of Languria is simply rounded and somewhat tapering, and neither produced nor with denticles. Tomolanguria also resembles the Neotropical genera Acropteroxys Gorham, 1887 and Langurites Motschulsky, 1860. Tomolanguria differs from Acropteroxys in having the pronotum finely punctured, with lateral side rounded, and apices of the elytra produced and bearing small denticles. Tomolanguria differs from Langurites in having the lateral side of pronotum rounded and the apices of the elytra with neither a sharp sutural angle nor an outer angle.

On the other hand, a similar structure of the elytra is demonstrated in the Oriental genus Paederolanguria Mader, 1939 and African genus Stenolanguria Fowler, 1885 (Fig. 3G, H). The new genus can be easily separated from the former by the following characters: 1) elytral epiplerura broader and more distinct; 2) apex of prosternal process bent sharply downward (Fig. 2G, H);3) mesoventrite without punctation and nearly smooth (Fig. 2B, C); 4) apex of elytra produced and with several small denticles (Fig. 2I, J); 5) abdomen without postmetacoxal lines. (Fig. 2D, E). Tomolanguria can be easily separated from Stenolanguria in having the head with fine punctures and the apex of elytra rounded; in Stenolanguria, the sutural angle is not produced and the outer angle of the elytra is produced and sharp, without denticles.

Etymology. The name is derived from the Greek word Touós (Latin transliteration as tomós, meaning "sharp", referring to the apex of the elytra) and the generic name Languria (as in Paederolanguria, Megalanguria, Caenolanguria, etc.). Gender feminine.

Distribution. Mexico, San Andrés Tuxtla.

Included taxa. Only one species.

\section{Tomolanguria aculeata (Gorham, 1887), comb. nov.}

Figure 1A-L

Languria aculeata: Gorham 1887: 11, tab. I, fig 17; Fowler 1908: 29; Schenkling 1928: 16; Blackwelder 1945: 426; Martins and Perreira 1965: 154.

Type locality. Mexico, San Andrés Tuxtla.

Redescription. Body length 8.5-9.5 mm. Body narrow and elongate, moderately convex. Integument finely and sparsely punctured. Head pitch black. Antenna brown except for last five antennomeres yellowish. Prothorax orange. Basal third of elytra coppery green or metallic blue, remainder deep brown or black, without metallic luster. 


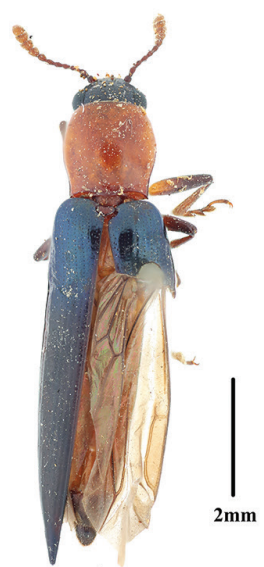

A

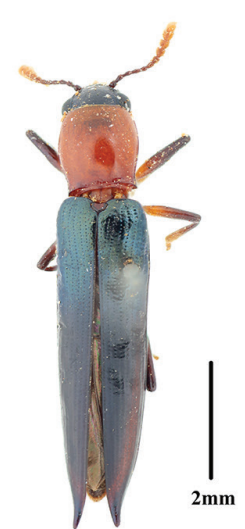

$\mathbf{E}$

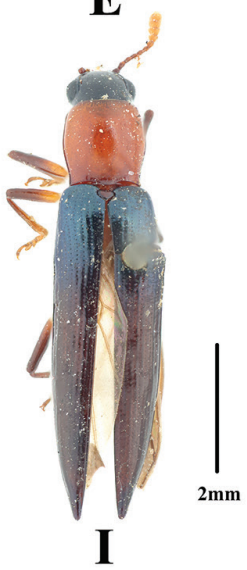

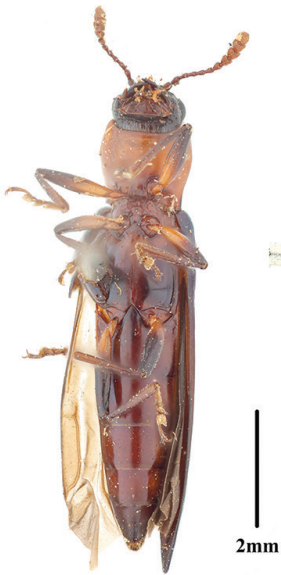

B
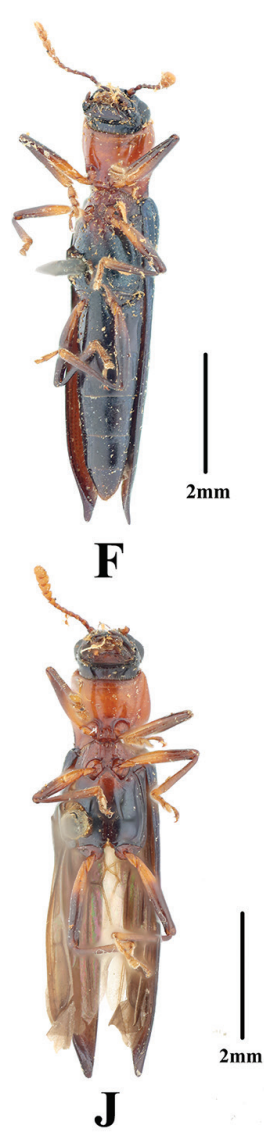

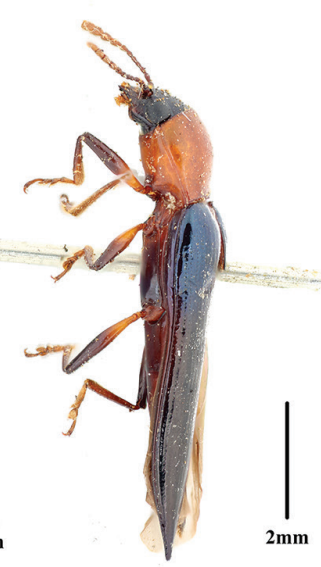

C
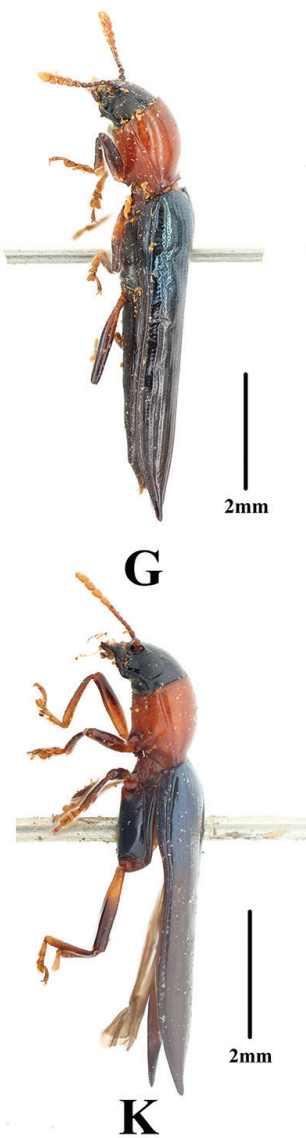

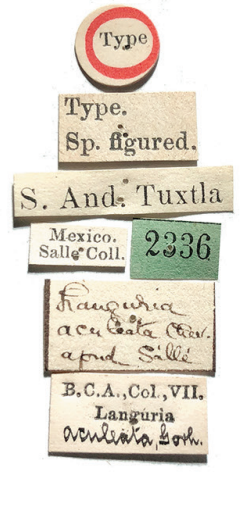

D

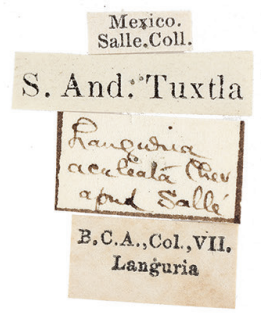

$\mathbf{H}$

Mexico.

S. And-. Tuxtla

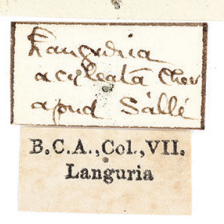

$\mathbf{L}$

Figure I. Tomolanguria aculeata (Gorham, 1887), comb. nov. A-D lectotype of T. aculeata: A dorsal habitus B ventral habitus $\mathbf{C}$ lateral view $\mathbf{D}$ labels $\mathbf{E}-\mathbf{H}$ paralectotype of $T$. aculeata: $\mathbf{E}$ dorsal habitus $\mathbf{F}$ ventral habitus $\mathbf{G}$ lateral view $\mathbf{H}$ labels $\mathbf{I}-\mathbf{L}$ second paralectotype of $T$. aculeata: I dorsal habitus J ventral habitus $\mathbf{K}$ lateral view $\mathbf{L}$ labels. Scale bars: $2 \mathrm{~mm}$. 


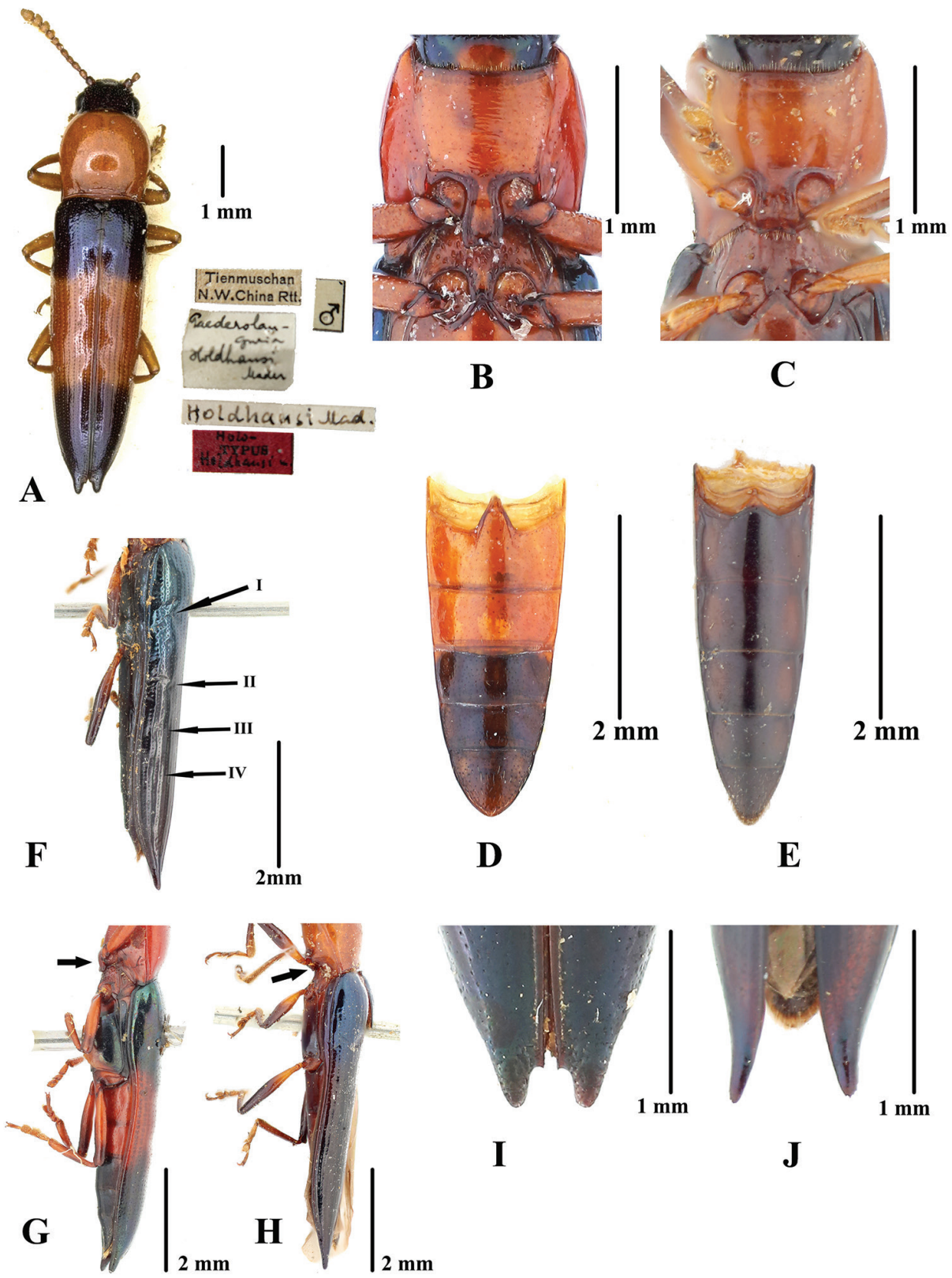

Figure 2. Comparison between Paederolanguria holdhausi Mader, 1939 and Tomolanguria aculeata (Gorham, 1887), comb. nov. A Holotype of Paederolanguria holdhausi Mader, 1939 B P. holdhausi, prosternum and mesoventrite with punctures, non-type $\mathbf{C}$ T. aculeata, prosternum and mesoventrite without punctures, paralectotype $\mathbf{D}$ P. holdhausi, abdomen, non-type $\mathbf{E}$ T. aculeata comb. nov., abdomen, paralectotype $\mathbf{F}$ lateral view of $T$. aculeata, black arrows show the depressions on the elytron, paralectotype $\mathbf{G}$ later view of body of $P$. holdhausi, black arrow shows the prosternal process nearly straight, non-type $\mathbf{H}$ same of $T$. aculeata, black arrow shows the prosternal process downwards, paralectotype I $P$. holdhausi, apex of the elytra, nontype J T. aculeata comb. nov., apex of elytra, paralectotype. Scale bars: $1 \mathrm{~mm}(\mathbf{A}-\mathbf{C}, \mathbf{I}, \mathbf{J}) ; 2 \mathrm{~mm}(\mathbf{D}-\mathbf{H})$. 


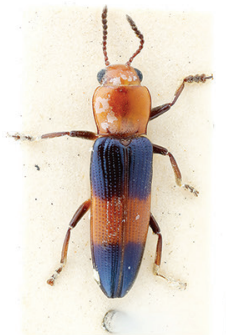

A

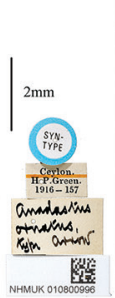

$\mathrm{B}$

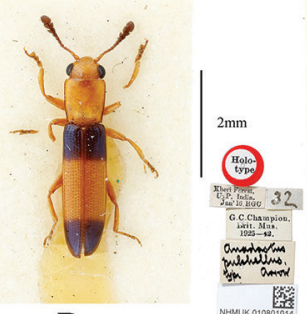

B

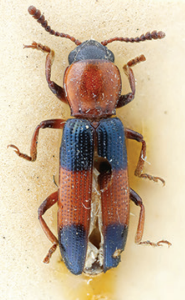

$\mathrm{C}$

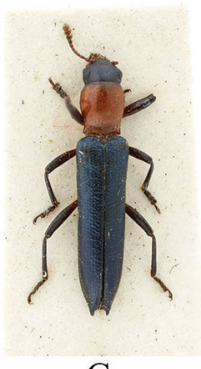

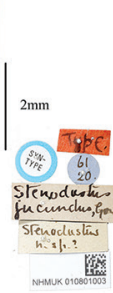

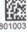

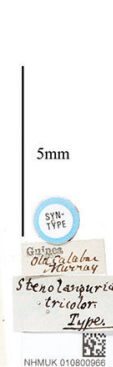

G

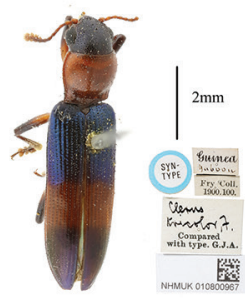

$\mathrm{D}$

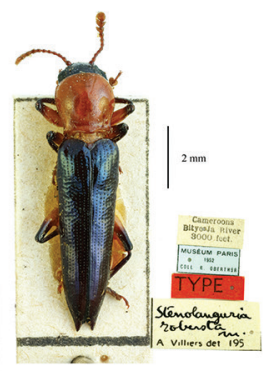

$\mathrm{H}$

Figure 3. Body of species from different genera of Languriinae that may imitate genus Paederus. A Anadastus ornatus Arrow, 1925, syntype B A. pulchellus Arrow, 1925, holotype C A. jucundus (Gorham, 1903), syntype, synonym of $A$. bifasciatus (Motschulsky, 1860) D Clerolanguria tricolor (Fabricius, 1787), syntype E Paederolanguria alternata (Zia, 1959), holotype F P. klapperichi Mader, 1955, holotype G Stenolanguria tricolor Fowler, 1885, syntype $\mathbf{H}$ S. robusta Villiers, 1958, holotype. Scale bar: $2 \mathrm{~mm}$ (A-D, H); $1 \mathrm{~mm}(\mathbf{E}, \mathbf{F}) ; 5 \mathrm{~mm}(\mathbf{G})$.

Antenna with 11 antennomeres and club composed of five fringed antennomeres. Antennomere III almost as long as antennomere IV, antennomere V subequal to antennomere VI, both of them shorter than each of antennomeres III or IV, antennomere VII subtriangular but slightly dilated, antennomeres VIII-XI dilated, apex of antennomere XI rounded. Head with fine punctation, nearly smooth. Clypeus broader than long. Eyes large, finely faceted. Mandibles robust and with outer side nearly straight.

Pronotum slightly convex, distinctly longer than broad, with sides rounded, constricted at the base. Pronotum finely punctured, without basal foveae. Anterior angle rounded, posterior angle acute but not produced. Lateral and basal margins beaded. Prohypomera smooth, without punctation or folds. Prosternal process long, with apex strongly bent downwards. Procoxal cavities open. Mesoventrite without punctation, nearly smooth (Fig. 2C).

Scutellar shield short and cordiform, apex not acute. Elytra regularly striate-punctate, vanishing before apex. Elytral epipleura distinct, narrow. Elytra at humeri slightly broader than base of pronotum. Sides of elytra parallel, narrowed posteriorly. Each elytron with four shallow transverse depressions (Fig. 2F). Elytral apex distinctly pro- 
duced and acute, laterally curved, with four or five coarse denticles (Fig. 2J). Abdomen finely punctured, postmetacoxal lines absent (Fig. 2E).

Material examined. Lectotype (BMNH), female, here designated, labeled: "Type" [circular label with red margin]// "Type. /Sp. figured." // "S. And. Tuxtla” // "Mexico./ Salle Coll."// "2336" [green label]// "Langurial aculeata Chev./ apud Salle" [handwriting]// "B. C. A., Col., VII./ Langurial aculeata, Gorh.”(Fig. 1D). Paralectotypes $(\mathrm{BMNH})$, two females, with the same labels (Fig. 1H, L).

Distribution. Mexico, San Andrés Tuxtla.

\section{Discussion}

The potential mimicry between Languriinae and Staphylinidae has been recorded (Mader 1939; Reid et al. 1994). When Mader (1939) erected the genus Paederolanguria, which was named after the genus Paederus Fabricius, 1775, he designated $P$. holdhausi (Fig. 2A) as the type species and mentioned that it displayed a color pattern similar to that in species of Paederus. (Staphylinidae). Reid et al. (1994) also reported a similarity between an undetermined species of Languriinae and Paederus from Java. The specimens examined in this study and an additional search of the Internet shows that such a mimic phenomenon is not rare in Languriinae and that it demonstrates two different forms. Some languriines show only the characteristic color pattern of Paederus, with red and alternative blue or dark stripes, including several species from the genus Anadastus Gorham, 1887 (Fig. 3A-C): Clerolanguria tricolor (Fabricius, 1787) (Fig. 3D), and Languria trifasciata Say, 1823. Some others not only have the similar color pattern but also somewhat modified structure, such as their bodies are more slender, with antennae not very dilated, pronotum rounded, elytra with weak transverse depressions, and elytral apex more or less produced or acute, which can be observed in species from the genera Paederolanguria, (Fig. 3E, F), Stenolanguria (Fig. 3G, H), and Tomolanguria (Fig. 1A, E, I).

After discussion with Dr José Luis Navarrete-Heredia, a specialist of Staphylinidae, we suggest that Paederus signaticornis Sharp, 1886 should be a suitable model for Tomolanguria aculeata (Fig. 4A, B). Both P. signaticornis and T. aculeata share the same distribution in Mexico, and the elytral color pattern of $T$. aculeata matches with that of $P$. signaticornis. For example, the basal third of the elytra of T. aculeata with a green metallic luster mimics the elytral color of $P$. signaticornis, the remaining part of the nearly black elytra mimics the color of the staphylinid abdomen. Besides, the color pattern and depressions on the elytra probably mimic the segmentation of the abdomen, and the produced apex of elytra may mimic tergite IX of $P$. signaticornis.

The genus Paederus is famous for their toxic, paederus dermatitis (Frank and Kanamitsu 1987). Kellner and Dettner (1996) suggested that the toxin is the basis for prey rejection. Their classic color pattern may be an example of aposematism, a warning signal to potential predators. Languriines may imitate the warning signals, even the appearances of Paederus, as an anti-predator strategy. In summary, we suppose that there may be a potential mimic relationship between this new genus Tomolanguria and genus Paederus. 

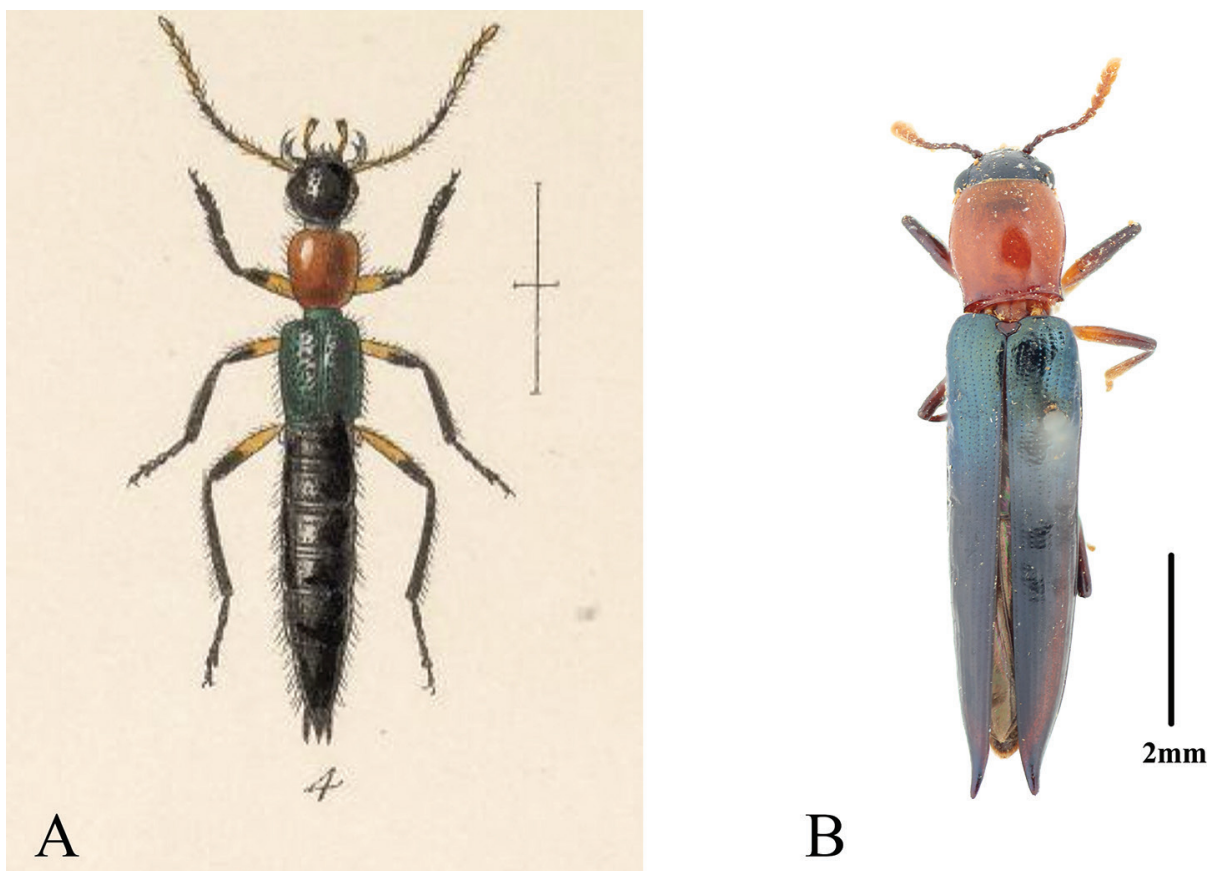

$\mathrm{B}$

Figure 4. Comparison between Paederus signaticornis Sharp, 1886 and Tomolanguria aculeata (Gorham, 1887), com. nov. A habitus of P. signaticornis (from Sharp 1886: pl. XVI, fig. 4) B habitus of T. aculeata comb. nov. Scale bars: $2 \mathrm{~mm}$.

\section{Acknowledgements}

We sincerely thank Mr Maxwell Barclay (BMNH) for the loan of Languriinae specimens, Dr Eva Sprecher (NHMB) for providing the photographs of the holotypes of Paederolanguria holdhausi and P. klapperichi, Dr Thierry Deuve (MNHN) for access to collections and loans of specimens, and Dr José Luis Navarrete-Heredia for helping us to find the mimic model. We also grateful to Ms Dione Serripieri (Museu de Zoologia da Universidade de Sáo Paulo) and Dr Peterson L. Lopes (Instituto Federal de Educação, Ciência e Tecnologia de São Paulo), who kindly send us the references of Martins and Perreira. Thanks are also due to Dr Ottó Merkl and Dr Alexander G. Kirejtshuk for their helpful comments. This study was supported by a Grant for the Key Foreign Cooperation Projects of the Bureau of International Cooperation of the Chinese Academy of Sciences (152111KYSB20160067).

\section{References}

Blackwelder RE (1945) Checklist of the coleopterous insects of Mexico, Central America, the West Indies, and South America. Part 3. Bulletin of the United States National Museum 185: i-iv, 343-550. https://doi.org/10.5479/si.03629236.185.3 
Frank JH, Kanamitsu K (1987) Paederus, Sensu Lato (Coleoptera: Staphylinidae): natural history and medical importance. Journal of Medical Entomology 24(2): 155-191. https:// doi.org/10.1093/jmedent/24.2.155

Fowler WW (1908) Coleoptera fam. Erotylidae subfam. Languriinae. In: Wytsman P (Ed.) Genera Insectorum. Vol. 78. P. Wytsman, Bruxelles, 1-45.

Gorham HS (1887) Erotylidae, Endomychidae and Coccinellidae. In: Porter RH (Ed.) Biologia Centrali-Americana. Insecta. Coleoptera, Vol. III. Taylor \& Francis, London, 276 pp.

Kellner RLL, Dettner K (1996) Differential efficacy of toxic pederin in deterring potential arthropod predators of Paederus (Coleoptera: Staphylinidae) offspring. Oecologia 107(3): 293-300. https://doi.org/10.1007/BF00328445

Mader L (1939) Neue Coleopteren aus China. Entomologisches Nachrichtenblatt 13: 41-51.

Martins UR, Perreira FS (1965) Revisão dos Languriinae neotropicais (Coleoptera, Languriidae). Archivos de Zoologia do Estado de São Paulo 13: 139-300.

Navarrete-Heredia JL, Newton AF, Thayer MK, Ashe JS, Chandler DS (2002) Guía Ilustrada para los Géneros de Staphylinidae (Coleóptera) de México. Illustrated Guide to the Genera of Staphylinidae (Coleóptera) of Mexico. Universidad de Guadalajara and CONABIO, Mexico, 401 pp.

Reid CAM, Noerdjito WA (1994) Mimicry of a Paederus species (Col., Staphylinidae) by a species of Languriinae (Col., Languriidae) in Java. Entomologist's Monthly Magazine 130: 63-65.

Schenkling S (1928) Languriidae. In: Junk W, Schenkling S (Eds) Coleopterorum Catalogus, Pars 100, W. Junk, Berlin, 40 pp.

Sharp D (1886) Fam. Staphylinidae. Biologia Centrali-Americana. Insecta, Coleoptera. Vol. 1. Part 2. Taylor \& Francis, London, 537-672. [pls 14-17] https://biodiversitylibrary.org/ page/577032 